\title{
A suitable metocean hindcast database for the design of Marine energy converters
}

\author{
Edwige Boudière $^{\mathrm{a}, *}$, Christophe Maisondieu ${ }^{\mathrm{a}}$, Fabrice Ardhuin ${ }^{\mathrm{a}}$, Mickaël Accensi ${ }^{\mathrm{a}}$, \\ Lucia Pineau-Guillou ${ }^{a}$, Jérémy Lepesqueur ${ }^{b}$
}

\begin{abstract}
a IFREMER, Centre Bretagne - ZI de la Pointe du Diable - CS 10070 - 29280 Plouzané - France
${ }^{\mathrm{b}}$ CNRS, Laboratoire de Physique des Océans, UMR6523 CNRS, Ifremer, IRD, UBO, ZI de la Pointe du Diable, CS10070, 29280 Plouzané
\end{abstract}

*: Corresponding author : Edwige Boudière, email address : edwige.boudiere@gmail.com

\begin{abstract}
:
Resource assessment as well as characterisation of site climatologies for the design of Marine Energy Converters requires data bases allowing an accurate description of the environmental forcing, especially waves and sea-states, on a high resolution grid. As a support to its research activities related to the development of marine renewable energies, Ifremer is building a specific hindcast data set for the assessment of sea-states climatologies. The main features of this database, built running an up-to-date configuration of the WaveWatch III ${ }^{\circledR}$ wave model on an unstructured grid extending from the South of the North Sea to the Bay of Biscay are presented here. Attention is given to the parameterization and forcing as well as the specific output data sets and validation processes.
\end{abstract}

Keywords : Directional spectra ; Hindcast ; WAVEWATCH III ${ }^{\circledR}$; Marine renewable energy

\section{Introduction}

Waves constitute the dominant environmental forcing element for the design of marine structures and especially for the design of Marine energy converters (MEC). Not only waves represent a major renewable resource of marine energy which, to be harnessed, requires the development of optimized devices, but they also will affect the efficiency and structural aging of any device, including off-shore wind turbines or current turbines deployed in the open sea.

Hence, beyond the problem of resource assessment, acute needs exist for refined wave climatologies adapted to the specific requirements of engineering and design studies.

These climatologies should provide all the necessary information on space-time variability of seastates at the local scale of a production site [1] together with a complete characterisation of the 
spectro-directional distribution of the energy within a sea-state [2]. Therefore new databases are required, built on refined grids and including full wave directional spectra.

As a support to its research and engineering activities related to the development of marine renewable energies, Ifremer initiated a project with the objective of building a specific hindcast data set for the assessment of sea-states climatologies that fulfils such requirements for MEC design and optimisation.

As a first step of this project, a sea-states hindcast database covering the Channel and Bay of Biscay over a 19 years period from 1994 to 2012 is built running an up-to-date configuration of the Wavewatch $\mathrm{III}^{\circledR}$ (WW3) wave model on a refined unstructured grid and providing directional spectra at over 4000 locations.

The parameterization, grid and forcing used to run the wave model are described in the first part of the paper. The output parameters and data sets are then detailed. Finally preliminary validation results are presented showing the good agreement of the simulations with in-situ measurement, satellite data and one other validated wave model.

\section{Wave hindcast model}

\section{A. Wave Model description}

\section{1) Parameterization}

The data sets are obtained running the WW3 code in its version 4.09. WW3 is a phase-averaged wave model resolving the random phase spectral action density balance equation for wavenumber-direction spectra. An explicit propagation scheme for unstructured grid is used ([3], [4]). The mesh is unstructured with a resolution ranging from $200 \mathrm{~m}$ to $10 \mathrm{~km}$, adapted at various scales from the open sea to the shore. The mesh was built merging sub-areas, or polygons (see Fig. 1), having different refinements. For all these areas, criteria for grid resolution refinement take into account both the depth variation and the propagation velocity (CFL criterion). These criteria allow an optimisation of the computation time by limiting the minimum length of the smallest triangle meshes. The MAXDZ depth related criterion is defined so that

$$
A_{\text {new }}=\frac{M A X D Z}{D Z} A_{\text {old }}
$$

where $A_{\text {new }}\left(m^{2}\right)$ is the area of the new calculated triangle element, MAXDZ $(m)$ is the maximum allowed variation of depth in each triangle element (user defined constant), DZ $(m)$ is the depth variation in the area $A_{\text {old }}\left(\mathrm{m}^{2}\right)$.

The CFL criterion is defined by : 


$$
C_{g} \Delta t=\Delta x
$$

where $\mathrm{C}_{\mathrm{g}}(\mathrm{m} / \mathrm{s})$ is the limit group velocity, $\Delta \mathrm{t}(\mathrm{s})$ is the time step and $\Delta \mathrm{x}(\mathrm{m})$ is the grid length scale.

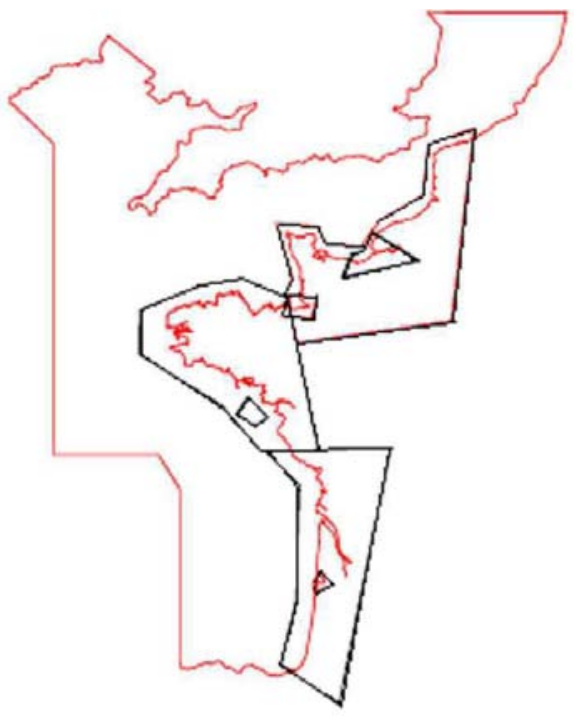

Fig. 1 Computational mesh polygons

The grid is composed of over 110000 nodes and covers a large domain, from the south of the North Sea to the Bay of Biscay.

The parameterization for wave generation and dissipation ([5], [6]) used in this configuration has been developed in the framework of the IOWAGA (Integrated Ocean WAves for Geophysical and other Applications) project and is used in the PREVIMER operational forecast model demonstrator [7].

The nonlinear wave evolution and interactions are modelled using the Discrete Interaction Approximation [8]. Improvement of the parameterization of the wave breaking is based on observations ([5], [6]) and makes the distinction between spontaneous breaking (breaking of steep waves) and induced breaking (long breaking waves overtaking shorter waves).

The parameterization of the interaction of waves with a sandy bottom includes ripples generation and relict ripple roughness [9] using the sub-grid roughness algorithm by Tolman [10]. This model is based on the ripple roughness predictor from Grant and Madsen [11], elaborated from laboratory data and extended to spectral waves [12] within the sheet flow regime [13] and is representative for irregular waves. It allows a fractional ripple coverage for the grid box and was modified so as to take a better account of the relict roughness and extended so as to take into account the variability of the bottom nature.

Coastal reflection is parameterized introducing a variable reflection coefficient defined from the shoreface slope and depending on the geomorphology of the shoreline and wave characteristics (incident wave height and mean frequency). Such a parameterization reduces errors on the mean directional spreading in areas where the shoreface slope can be accurately estimated [14].
The computed spectra are discretised over 24 directions $\left(15^{\circ}\right)$ and 32 frequencies (ranging from $0.0373 \mathrm{~Hz}$ to 0.7159 $\mathrm{Hz})$.

\section{2) Bathymetry}

The domain of the model extends from the South of the North Sea to the North of Spain covering the whole continental shelf in the Bay of Biscay. The high resolution bathymetry used in this configuration combines the data from SHOM (Service Hydrographique et Océanographique de la Marine) for the coastline and from surveys conducted by IFREMER and SHOM for the bathymetry (MNT $100 \mathrm{~m}$ and $500 \mathrm{~m},[15])$. Some limited areas such as Bassin d'Arcachon (data from BRGM (Bureau de Recherches Géologiques et Minières)), Bay of Veys, Les Minquiers shoal and La Gironde estuary were corrected using data from specific bathymetry surveys.

\section{3) Source wind field}

The wave model is forced by the wind field from the CFSR reanalysis (Climate Forecast System Reanalysis, [16]) that was produced at NCEP (National Centre for the Environmental Prediction) in 2010. This $10 \mathrm{~m}$ wind field is a reanalysis over a 31 years period from 1979 to 2009 with a spatial resolution ranging from $0.25^{\circ}$ at the equator to $0.5^{\circ}$ at higher latitudes.

Wave data produced by other wave models forced using this wind field proved to compare well with both satellite altimeters and buoy measurement ([17], [18]) even though some of the highest wave events are sometimes under estimated.

The wind field is updated with a 6 hours time step.

\section{4) Water level and Currents}

Water levels, surges and currents have been computed using the MARS 2D (Model for Applications at Regional Scale) hydrodynamic model, based on the shallow water equations, that was developed at IFREMER [19]. This model is actually composed of seven embedded models with different refinements (rank 0, rank 1 and ranks 2; see details on Table I).

Recent improvements were made introducing elaborated sea surface drag parameterization and taking high resolution meteorological forcing into account. A sensitivity study of sea surface drag parameterization [20] showed that the wind and wave dependant parameterization [21] presents better result for storm surge modelling than constant sea surface drag or wind dependant parameterization, which is obtained from runs of the wave model WW3 and is integrated in the currents model configuration.

For the implementation of tides and tidal currents, the rank 0 model is forced by the sea surface height from the FES (2004) global tidal model [22] with 14 tidal components. The rank 1 is embedded in rank 0 and is then forced by the tides from rank 0 . The rank 2 models are forced by the tide from the cstFRANCE tidal model [23] with 115 tidal components, provided by SHOM. The rank 2 models are also forced by surges computed from rank 0 and rank 1 . This methodology 
allows an accurate evaluation of water levels and tidal currents at rank 2 .

Météo-France data are used for the meteorological forcing. Rank 0 and rank 1 models are forced using data from the $0.5^{\circ}$ ARPEGE meteorological model ([24], [25]), with a six hours time step. Since November 2011, ARPEGE is available with higher resolution $\left(0.1^{\circ}\right.$ and 1 hour time step). Rank 2 models are forced with the data from the $0.025^{\circ}$ AROME meteorological model [26], with a one hour time step.

In order to avoid the rather heavy handling of currents and water level data produced by the embedded models, choice was made to build atlases of harmonic components. A hindcast was produced over a one year period (2008) and analysed so as to produce tide and tidal currents harmonic components atlases for each of the seven models. Tides and tidal currents can then be predicted for any period of time over the whole domain. The tidal constituents and water levels are updated with a 30 minutes time step and interpolated on the wave model grid having the finest resolution.

TABLE I

DETAILS FOR WATER LEVEL AND CURRENT MODELS

\begin{tabular}{|c|c|c|c|c|}
\hline Rank & $\begin{array}{c}\text { Spatial } \\
\text { Resolution } \\
(\mathbf{m})\end{array}$ & $\begin{array}{c}\text { Temporal } \\
\text { Resolution } \\
\text { (min) }\end{array}$ & Model & Label \\
\hline 0 & 2000 & 60 & $\begin{array}{c}\text { North East } \\
\text { Atlantic }\end{array}$ & ATLNE2000 \\
\hline 1 & 700 & 60 & $\begin{array}{c}\text { Bay of Biscay } \\
\text { and the English } \\
\text { Channel }\end{array}$ & MANGA700 \\
\hline 2 & 250 & 15 & $\begin{array}{c}\text { Aquitaine } \\
\text { Coast }\end{array}$ & AQUI250 \\
\hline 2 & 250 & 15 & $\begin{array}{l}\text { East of the } \\
\text { English } \\
\text { Channel }\end{array}$ & MANE250 \\
\hline 2 & 250 & 15 & $\begin{array}{l}\text { West of the } \\
\text { English } \\
\text { Channel }\end{array}$ & MANW250 \\
\hline 2 & 250 & 15 & Iroise Sea & FINIS250 \\
\hline 2 & 250 & 15 & South Brittany & SUDBZH250 \\
\hline
\end{tabular}

\section{B. Outputs description}

The main objective of this hindcast database is to provide all the relevant information requested for building climatologies adapted to marine structures design studies and especially marine energy converters development. Whether considering resource assessment, structures design or even management of marine operations, global wave parameters must be provided on a refined grid, at the scale for instance of a production site, a few square kilometres. But more specifically, the dynamic response of such devices, hence their efficiency, are highly related to the spectro-directional distribution of the wave energy. Hence a major feature of this work is the production of a long duration time series and directional spectra on a refined grid.

\section{1) Gridded outputs}

Default WW3 wave model outputs include a large set of global wave parameters, such as the significant wave height, peak period and wave directions for instance.
Moreover, the model produces a partition of the wave systems constituting of a multi-modal sea-state and a set of standard field parameters (significant wave height, peak period and mean direction) for each swell and wind sea is provided.

Additional parameters are also produced as output to this configuration of the model that are of particular interest for :

- ocean engineering and marine renewable applications: wave energy flux $(\mathrm{CgE})$, mean period $\mathrm{Te}(\mathrm{tm} 0 \mathrm{~m} 1), \ldots$

- studies on sediment dynamics and wave-current interactions: RMS of bottom amplitude displacement (abr), RMS of bottom velocity amplitudes (ubr), radiation stresses (Sxy), surface Stokes drift (uss), stokes transport (tus), ...

- analysis of the air-sea fluxes and upper ocean mixing: wind to wave energy flux (faw), waves to ocean TKE flux (foc), ...

1D Frequency spectra (Energy Spectral Density) are also produced.

All these parameters and data sets are saved at each node of the high resolution unstructured computational mesh (over 110000 nodes) with a one hour time step.

\section{2) Directional spectra Outputs}

Marine energy devices are to be deployed in high energy areas, where the environmental conditions are not necessarily the harshest but can vary in space and time and can often be complex with multi-modal sea-states, superimposition of swell and wind sea and strong wave-current interaction.

Directional spectra provide the most comprehensive information on the distribution of wave energy within a seastate and as such are of great use for resource assessment and description of climatologies, especially when spectral bandwidth and directional spreading are to be characterized.

Saving all directional spectra at each node of the computational grid was simply not possible for practical reasons related to data handling and storage.

Nevertheless and with the objectives of use and exploitation of this database in mind, a coarser output grid was created, derived from the original computational mesh, on which directional spectra are saved at each time step. Extra control points were added: at the location of planned or already operational testing or deployment sites for marine energy converters (for instance SEMREV in France, Wave Hub in the UK or Bimep in Spain); also, for the purpose of validation, at the location of in-situ survey sites such as those of the CANDHIS network where directional buoys are deployed as well as at the coordinates of the NOAA/NCEP wave hindcast database output points (both $0.5^{\circ} \times 0.5^{\circ}$ and $1^{\circ} \mathrm{X} 1.25^{\circ}$ grids).

Altogether, directional spectra (24-directions x 32frequencies matrices) are saved at over 4000 locations (see Fig. 2) with a one hour time step. 


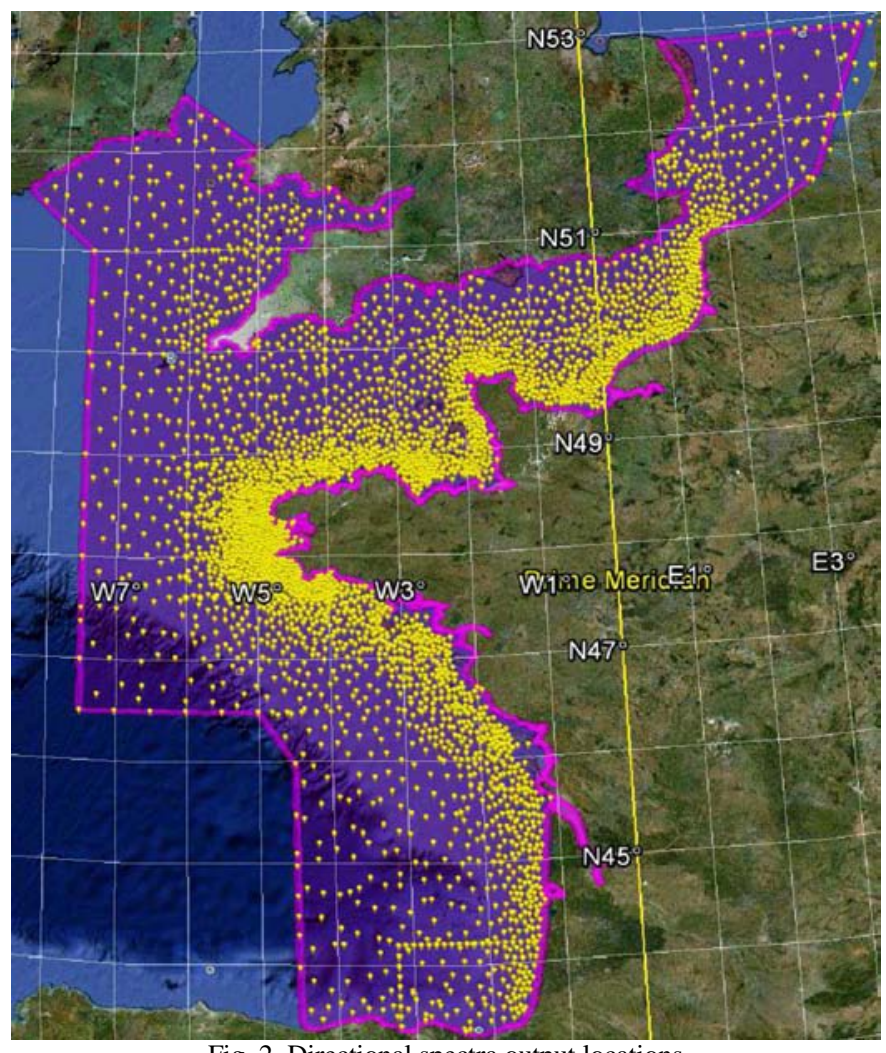

Fig. 2 Directional spectra output locations

\section{VALIDATION}

Data sets used for validation combine in-situ measurements from directional buoys, remote sensing from satellite altimeters and output from the NOAA/NCEP configuration of WW3.

\section{1) Buoy measurements}

A large set of in situ data from various sources, including ocean surveys is at disposal for validation purpose. Comparison was made with data from the Cetmef CANDHIS buoys network and Météo-France buoys along the French coast (see Fig. 3). The wave measurements were recorded as 20 or 30 minutes samples, twice per hour. Only one MétéoFrance buoy (62052) measured wind speeds recording a 10 minutes sample, once per hour. Wind and Wave measurement values were selected for comparison with the hourly hindcast data, assessing the standard metric errors: mean bias, centred root mean square error (CRMSE), scatter index (S.I.) and correlation (r). Results for significant wave height are presented Fig. 5 and 6 , and Table III and results for wind speed are presented Fig. 7 and Table IV.

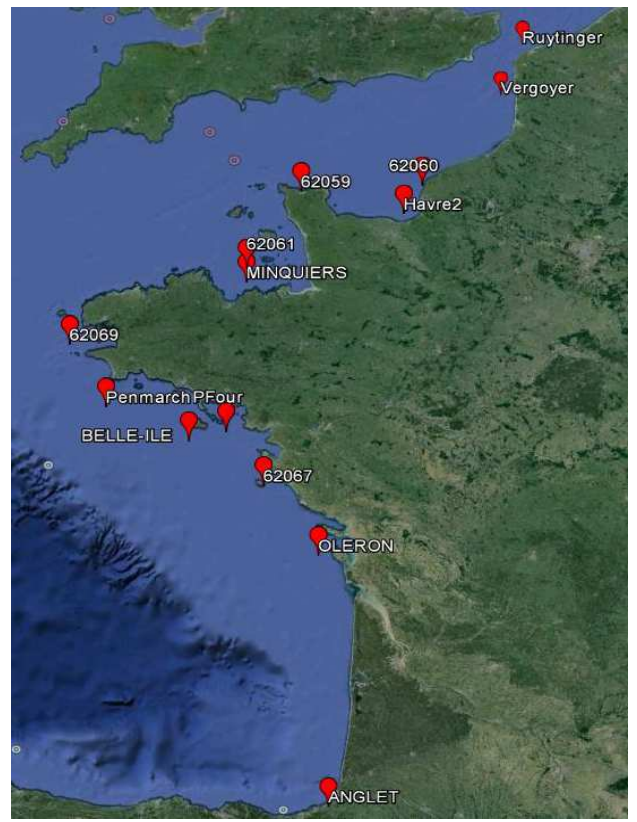

Fig. 3 Locations of the in-situ measurements

TABLE II

STATISTIC ERRORS FOR HS AT SELECTED BuOYS

\begin{tabular}{llllll} 
Buoy & Period & $\begin{array}{l}\text { Mean } \\
\text { Bias }(\boldsymbol{\%})\end{array}$ & $\begin{array}{l}\text { S.I. } \\
(\mathbf{m})\end{array}$ & CRMSE & r \\
\hline 62059 & $2005-2012$ & 15.3 & 0.18 & 0.24 & 0.93 \\
62060 & 2009 & 4.4 & 0.19 & 0.26 & 0.92 \\
62061 & $2004-2012$ & 9.9 & 0.23 & 0.20 & 0.93 \\
62067 & $2005-2012$ & 12.0 & 0.18 & 0.17 & 0.96 \\
62069 & $2008-2012$ & 11.1 & 0.30 & 0.15 & 0.97 \\
Anglet & $2009-2012$ & 3.4 & 0.30 & 0.16 & 0.96 \\
Belle-Ile & $2010-2012$ & 5.6 & 0.27 & 0.13 & 0.97 \\
Havre & 2010 & -3.3 & 0.20 & 0.20 & 0.93 \\
Minquiers & $2008-2009$ & -0.6 & 0.20 & 0.16 & 0.94 \\
Minquiers & $2011-2012$ & -9.1 & 0.17 & 0.15 & 0.95 \\
(N) & & & & & \\
Oleron & 2010 & 8.2 & 0.27 & 0.15 & 0.96 \\
Penmarc'h & $2009-2010$ & 6.5 & 0.37 & 0.12 & 0.97 \\
Plateau du & $2010-2012$ & 3.7 & 0.20 & 0.14 & 0.97 \\
Four & & & & & \\
Ruytingen & 2010 & -0.6 & 0.28 & 0.23 & 0.89 \\
Vergoyer & $2010-2012$ & -7.4 & 0.22 & 0.22 & 0.95
\end{tabular}

TABLE III

STATISTIC ERRORS FOR WIND SPEED

\begin{tabular}{llllll} 
Buoy & $\begin{array}{l}\text { Number of } \\
\text { Points }\end{array}$ & $\begin{array}{l}\text { Bias } \\
(\boldsymbol{\%})\end{array}$ & $\begin{array}{l}\text { S.I. } \\
(\mathbf{m} / \mathbf{s})\end{array}$ & CRMSE & r \\
\hline 62052 & 6548 & 4.8 & 1.9 & 0.2 & 0.9
\end{tabular}

Statistics and plots (Fig. 5 and Fig. 6) show a good agreement overall with the observations. Correlation coefficient ranges between $89 \%$ and $97 \%$ for waves and is $90 \%$ for the wind indicating the model fits well the observations. The bias is also relatively low for the whole validation points and the scatter index and the CRMSE confirm the good agreement. 
The Quantile-Quantile (Q-Q) comparisons with wind speed and wave height confirm this agreement with the observations. However some underestimations for both the higher wind speeds and wave heights are noticeable, which appears to be a characteristic of the CFSR winds.

\section{2) altimeter data}

CERSAT database of wave and wind parameters from altimeters was used for this validation work. This database includes the ENVISAT, ERS1/2, TOPEX, JASON1/2 and GFO altimeters data (see details on Table IV) previously calibrated and corrected [27], which are used for this validation work.

Thanks to the high resolution of the global wave parameters output grid, data can be compared to the tracks of altimeters over the whole domain. Validation was done for the whole period of hindcast. The wave model has a time step of one hour. Thus, individual hindcast data points were interpolated in time onto the tracks of the altimeters. Statistics of errors are shown Table V and VI. Scatter diagrams and Q-Q comparisons for both wave height and wind speed are presented Fig. 8 and 9. Results are given for the whole set of available altimeters and show a good agreement for both the wind speed and wave height. However, plots show there are some underestimations for the higher wave heights and wind speeds. This trend is more accentuated for the wind speeds.

TABLE IV

DETAILS FOR ALTIMETERS

\begin{tabular}{llll} 
Satellite & Period & $\begin{array}{l}\text { Circle } \\
\text { Period } \\
\text { (Days) }\end{array}$ & Official Sources \\
\hline ERS1 & $1991-1996$ & 35 & CERSAT \\
ERS2 & $1995-2003$ & 35 & CERSAT \\
TOPEX & $1992-2005$ & 10 & AVISO, PODEX \\
POSEIDON & $2000-2008$ & 17 & NOAA \\
GFO & 2001 onwards & 10 & AVISO, \\
Jason 1 & & & PODAAC \\
Envisat & 2002 onwards & 35 & ESA \\
Jason 2 & 2008 onwards & 10 & NOAA, \\
& & & EUMESAT \\
\hline
\end{tabular}

TABLE V

WIND SPEED COMPARISON WITH ALTIMETERS

\begin{tabular}{llllll} 
Satellite & Period & $\begin{array}{l}\text { Mean } \\
\text { Bias } \\
(\mathbf{m} / \mathbf{s})\end{array}$ & $\begin{array}{l}\text { S.I. } \\
(\mathbf{m} / \mathbf{s})\end{array}$ & CRMSE & r \\
\hline ERS 1 & 1994 & -0.27 & 1.48 & 0.17 & 0.93 \\
ERS 2 & $1995-2010$ & 0.37 & 1.56 & 0.19 & 0.91 \\
ENVISAT & $2002-2012$ & 0.41 & 1.55 & 0.19 & 0.91 \\
TOPEX & $1994-2005$ & 0.25 & 1.61 & 0.19 & 0.9 \\
POSEIDON & $1994-2000$ & 0.87 & 1.97 & 0.22 & 0.87 \\
JASON 1 & $2002-2012$ & 0.57 & 1.58 & 0.19 & 0.9 \\
GFO & $2000-2008$ & 0.10 & 1.73 & 0.19 & 0.9 \\
JASON 2 & $2008-2012$ & 0.01 & 1.72 & 0.21 & 0.88
\end{tabular}

TABLE VI

SIGNIFICANT WAVE HEIGHT COMPARISON WITH ALTIMETERS

\begin{tabular}{llllll} 
Satellite & Period & $\begin{array}{l}\text { Mean } \\
\text { Bias } \\
(\boldsymbol{\%})\end{array}$ & S.I. (m) & CRMSE & r \\
\hline ERS 1 & 1994 & 6.1 & 0.40 & 0.14 & 0.97 \\
ERS 2 & $1995-2010$ & 7.0 & 0.33 & 0.14 & 0.97 \\
ENVISAT & $2002-2012$ & 3.6 & 0.28 & 0.12 & 0.98 \\
TOPEX & $1994-2005$ & 3.8 & 0.28 & 0.12 & 0.98 \\
POSEIDON & $1994-2000$ & 5.9 & 0.31 & 0.13 & 0.97 \\
JASON 1 & $2002-2012$ & 2.9 & 0.29 & 0.12 & 0.98 \\
GFO & $2000-2008$ & 4.1 & 0.29 & 0.11 & 0.98 \\
JASON 2 & $2008-2012$ & 3.1 & 0.29 & 0.12 & 0.97
\end{tabular}

\section{3) Comparison with NOAA's model}

NOAA provides a wave hindcast database covering the period from January 1997 to present. The global model had a $1^{\circ} \times 1.25^{\circ}$ resolution (Grid 1 on the Table) and was updated to a higher resolution $\left(0.5^{\circ} \times 0.5^{\circ}\right.$, Grid 2$)$ since 2005. Wave heights comparisons with NOAA's model were restricted to deep and intermediate water depth sites (see locations on Fig. 4). Table VII presents the interval of standard errors obtained for the whole set of selected points and Fig. 10 presents an exemple of plots of scatter diagrams and Q-Q comparisons for a site with a depth of $100 \mathrm{~m}$.

The statistics show a good agreement between the two models. For example, the value of the coefficient of correlation is over 0.94 and CRMSE is less than 0.2 for the whole set of selected points. This good agreement is confirmed by the scatter diagrams and Q-Q comparisons.

TABLE VII
STATISTIC ERRORS FOR SigNIFICANT WAVE HEIGHT

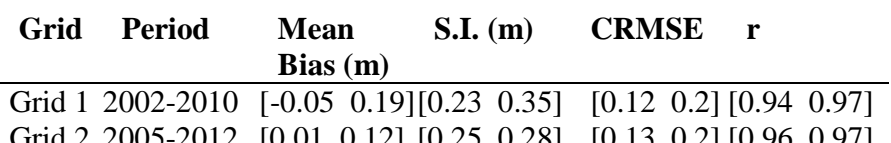

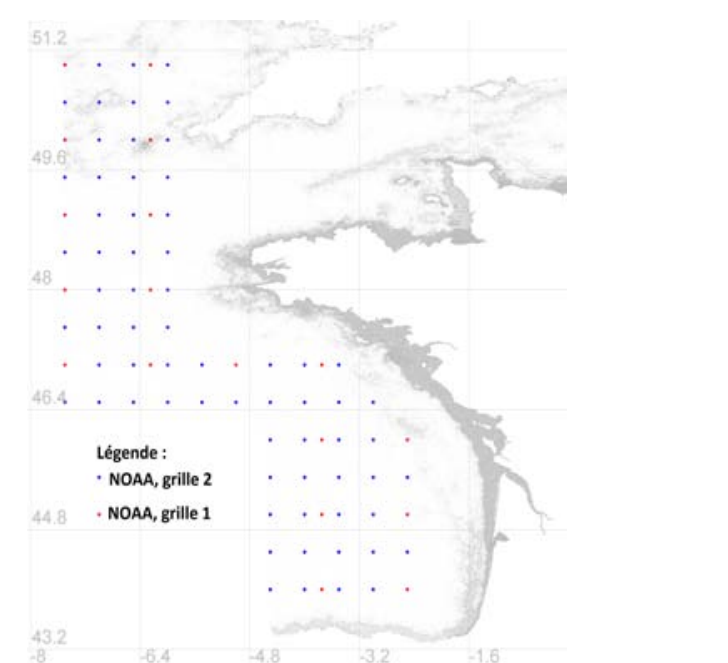

Fig. 4 Locations of NOAA's outputs

IV.CONCLUSIONS AND PERSPECTIVES 
The development of a new wave hindcast database adapted to the needs of the engineering and design studies for the optimization and operation of marine energy converters was presented.

This 19 years data set was built running an up-to-date configuration of the WW3 wave model extending over the Channel and Bay of Biscay. The main feature of this tool for the characterization of sea-states climatologies is its comprehensive set of parameters and directional spectra provided on a refined grid.
A good agreement was found when comparing significant wave height and wind speeds with in-situ measurement, altimeter data and NOAA's model. Further validation work is on-going based on directional spectra analysis.

Future work will include production of additional data sets for the Mediterranean Sea and the French Overseas territories.
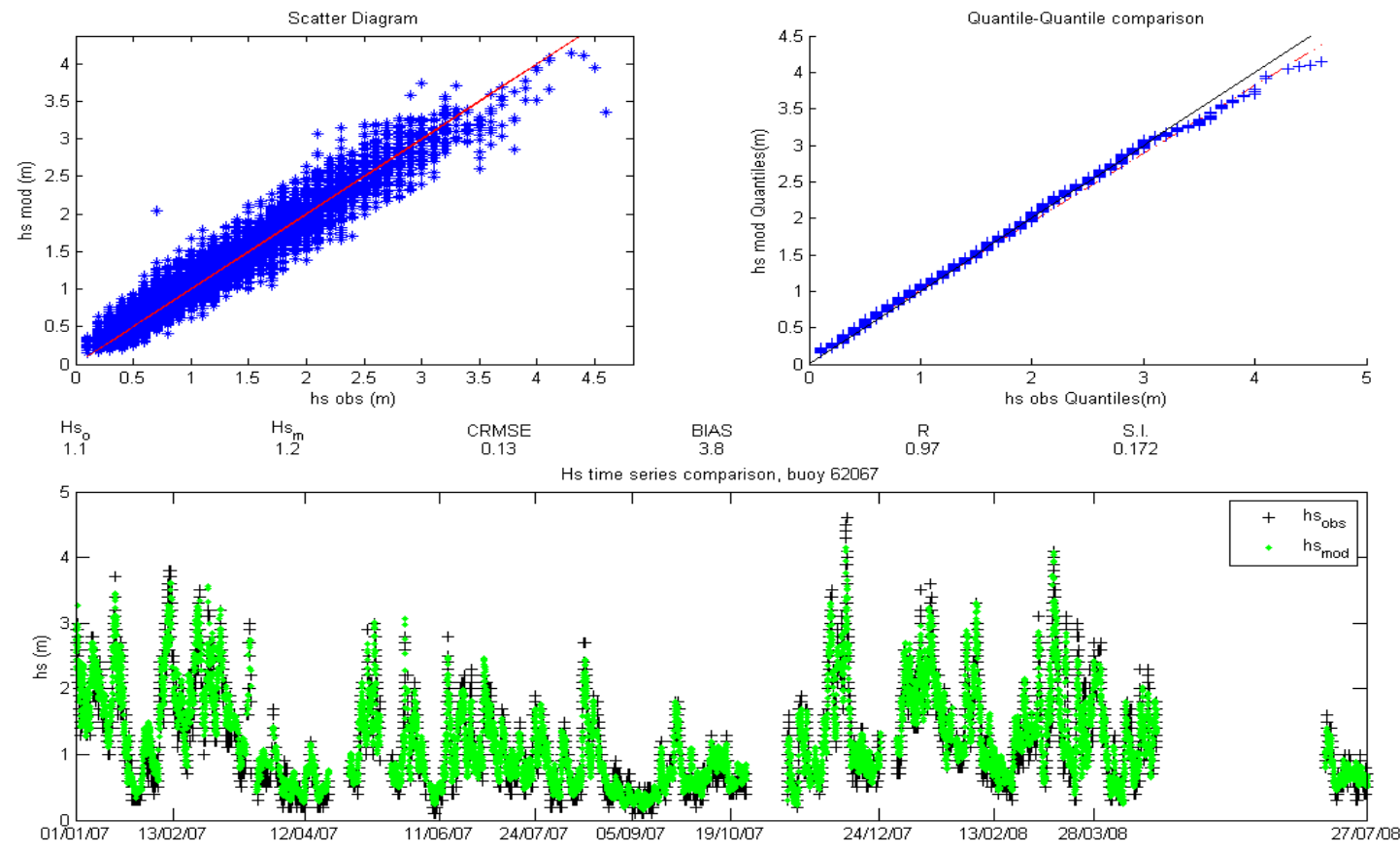

Fig. 5 Significant wave height - Comparison with buoy 62067 (CETMEF 2007-2008)
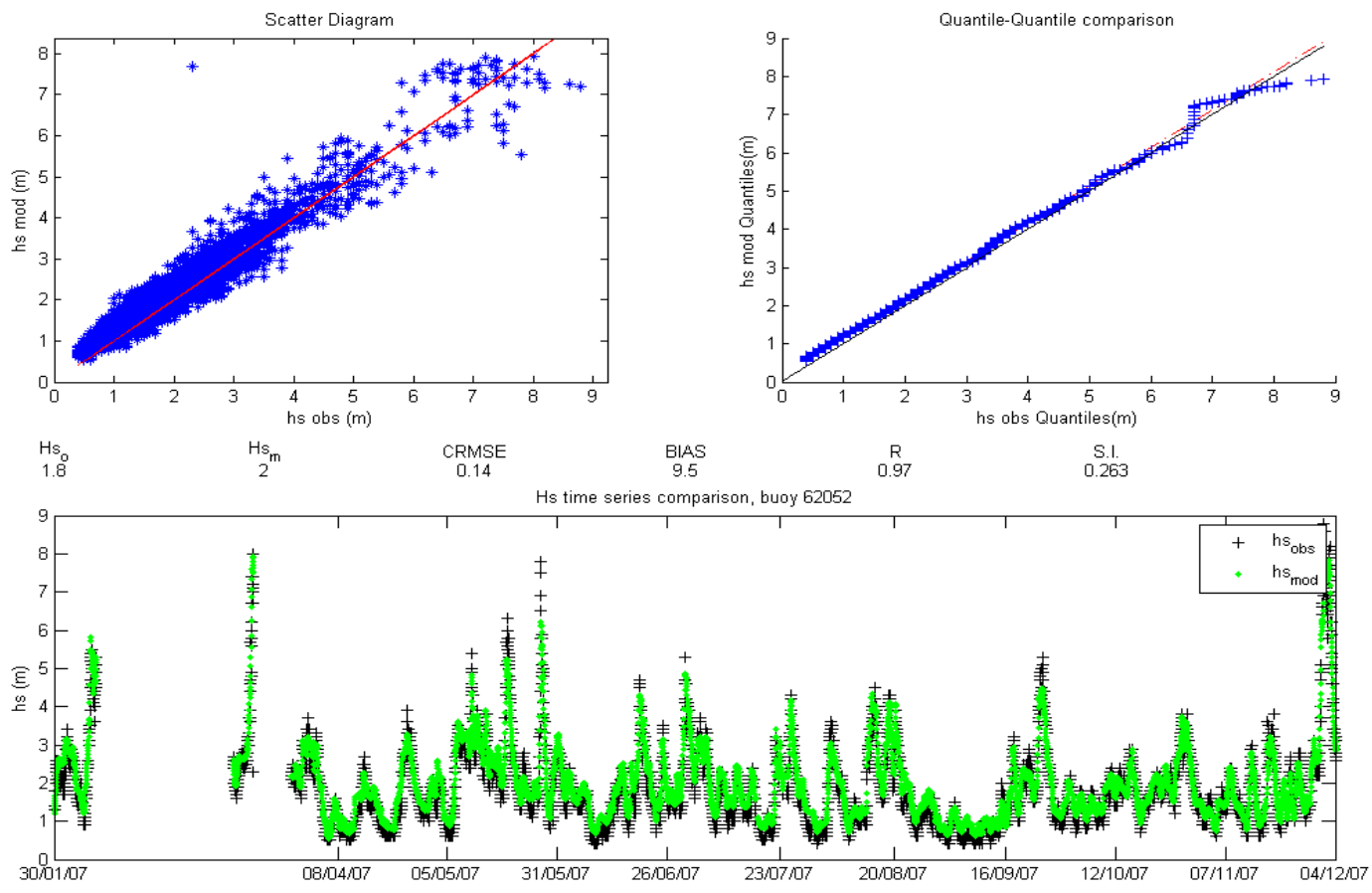

Fig. 6 Significant wave height - Comparison with buoy 62052 (Météo France 2007) 

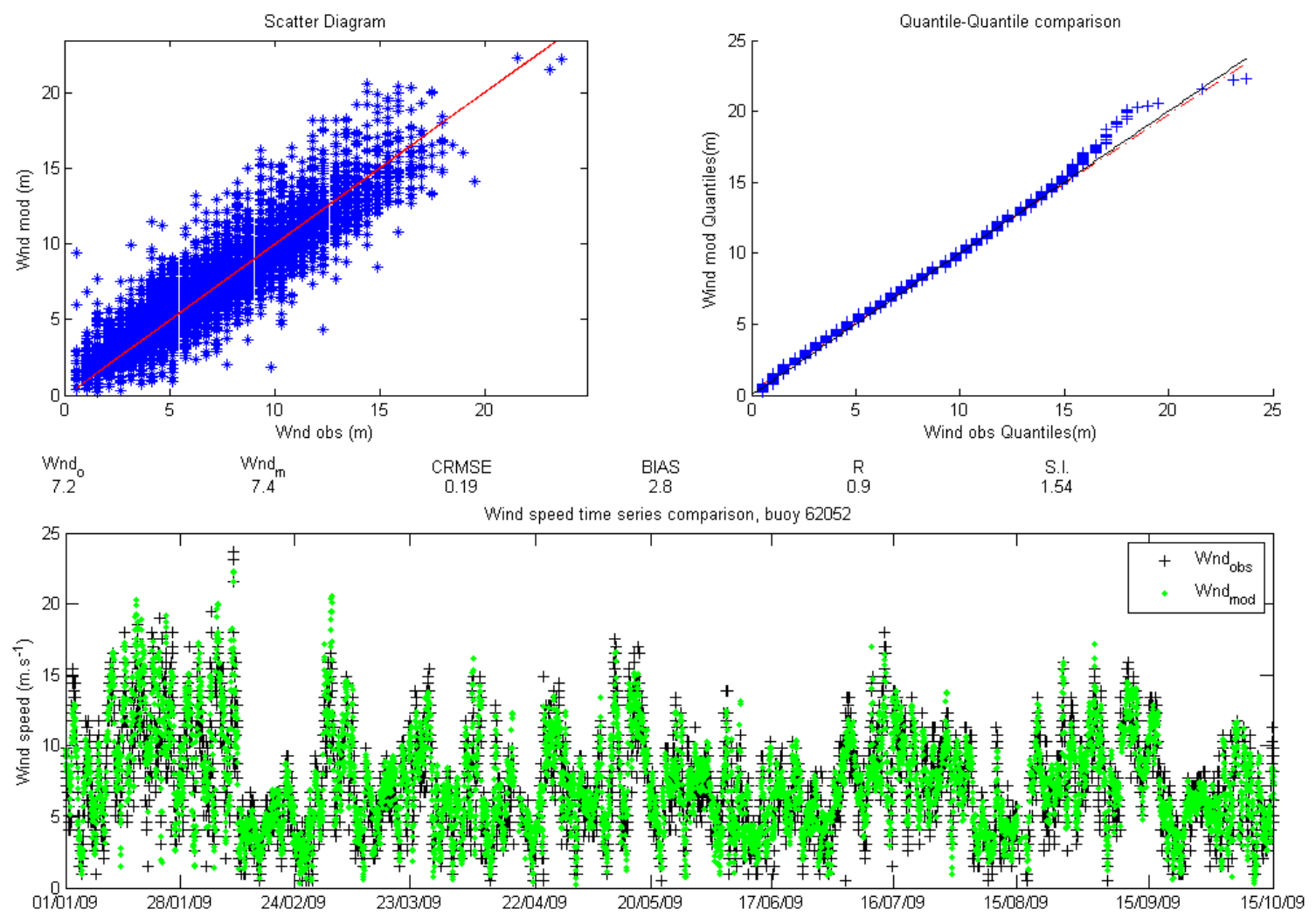

Fig. 7 Wind speed - Comparison with buoy 62060 (Météo France 2009)
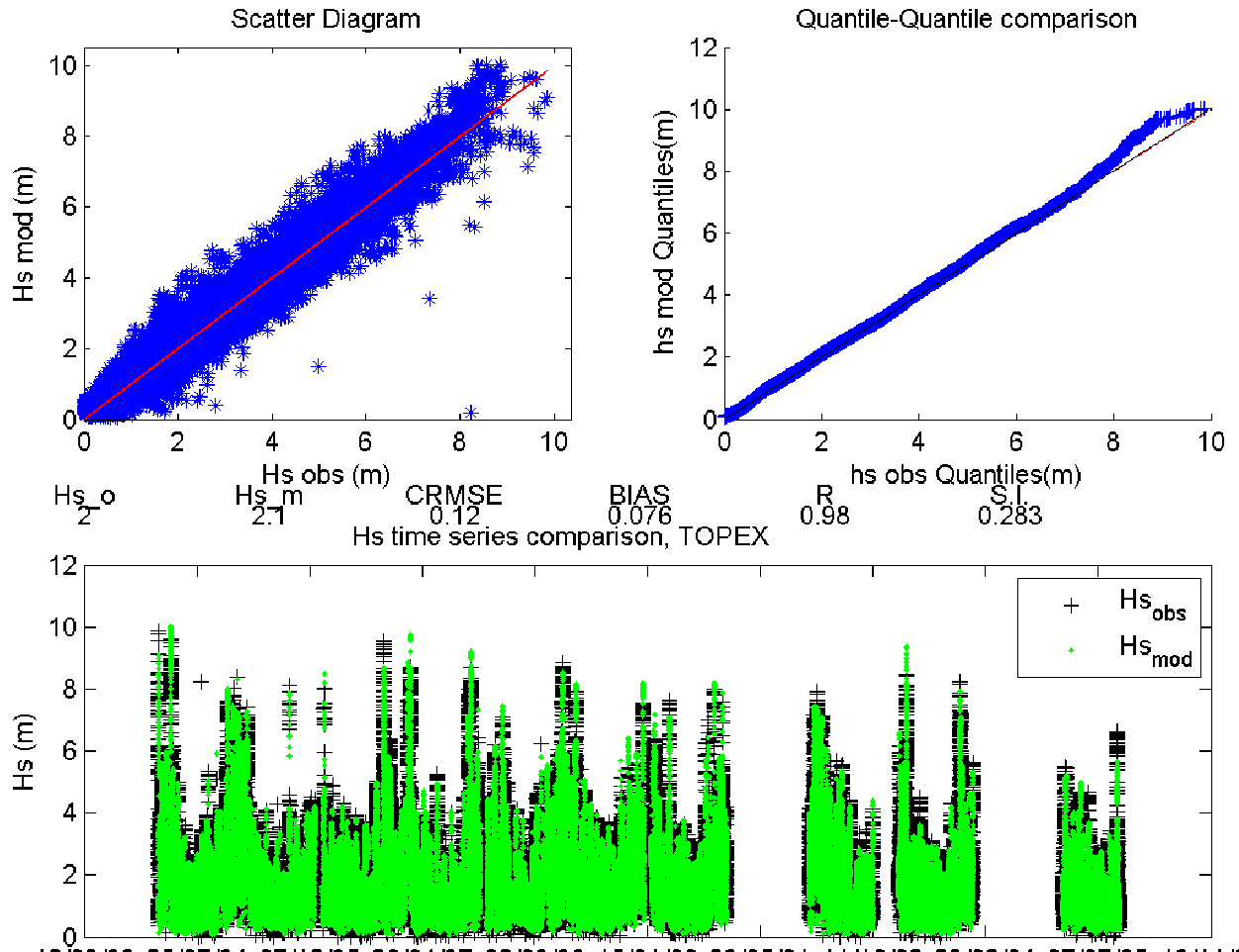

Rs obs Quantiles(m)

12/03/93 25/07/94 07/12/95 20/04/97 02/09/98 15/01/00 29/05/01 11/10/02 23/02/04 07/07/05 19/11/06

Fig. 8 Significant wave height - Comparison with the altimer TOPEX 

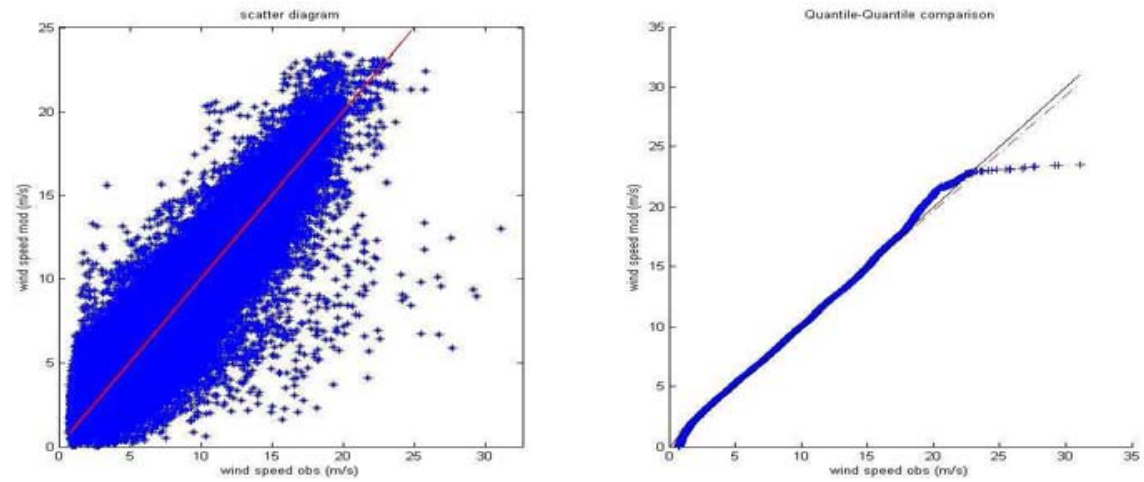

Fig. 9 Wind speed - Comparison with the altimeters merged for the period 2008-2009
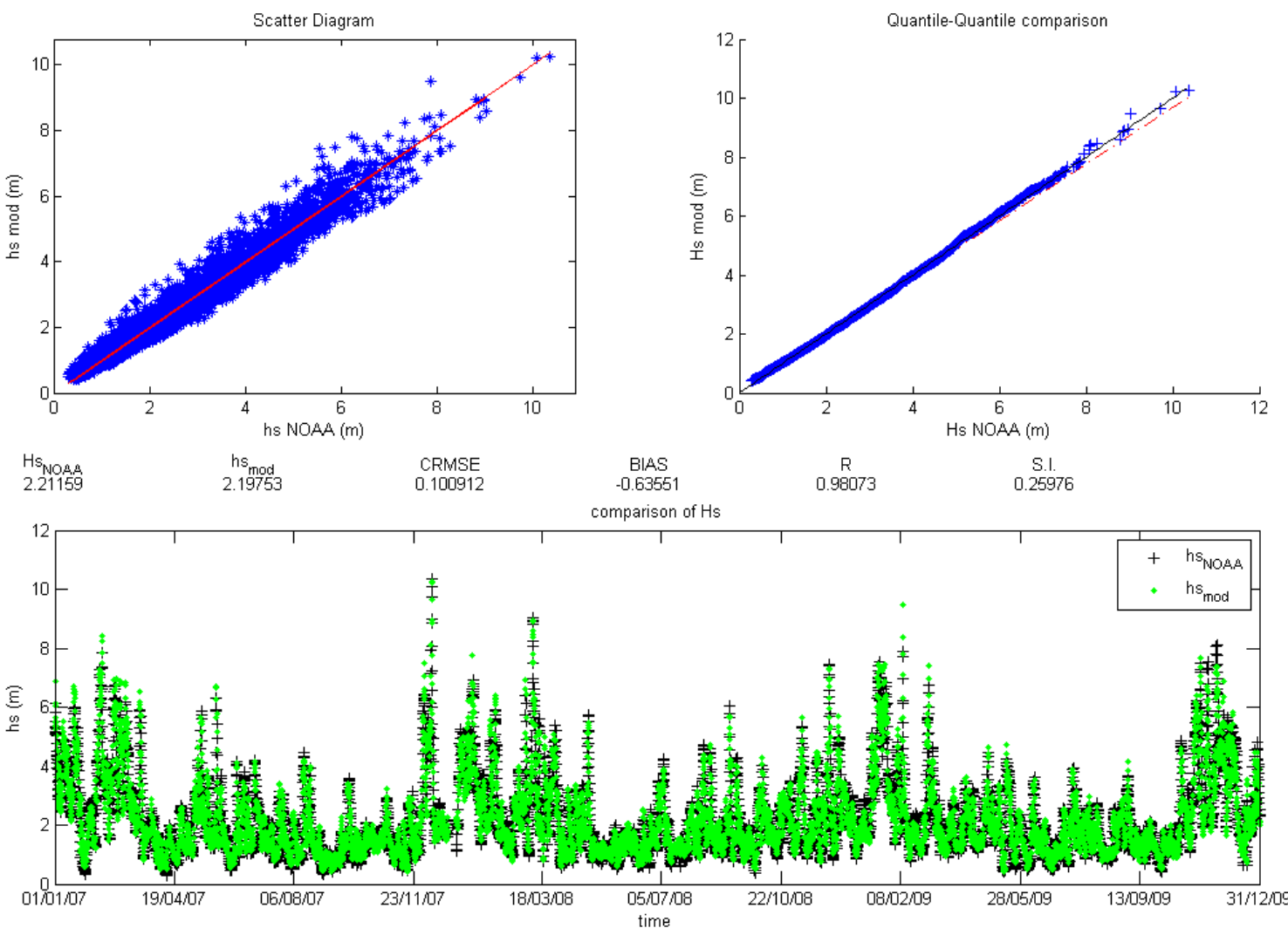

Fig. 10 Significant wave height - Comparison with NOAA/NCEP's model (coordinates $46.5^{\circ} \mathrm{N} 3.0^{\circ} \mathrm{W}$ )

\section{REFERENCES}

[1] Saulnier J-B., Maisondieu C., Ashton I., Smith G., "Refined sea state analysis from an array of four identical directional buoys deployed off the Northern Cornish coast (UK)", Applied Ocean Research, 37, 1-21, 2012

[2] Kerbiriou M-A., Prevosto M., Maisondieu C., Clément A., Babarit A., "Influence of Sea-States Description on Wave Energy Production Assessment", Proc. EWTEC Conf., Porto, Portugal, 2007.

[3] Roland A., "Development of WWM II: Spectral wave modelling on unstructured meshes", Ph. D. thesis, Inst. of Hydraul. and Wave Resour. Eng., Techn. Univer. Darmstadt, Germany, 2008.

[4] Roland A., A. Cucco, C. Ferrarin, T.-W. Hsu, J.-M. Liau, S.-H. Ou, G. Umgiesser, and U. Zanke, 2009, "On the development and verification of 2-D coupled wave-current model on unstructured meshes", J. Mar. Syst., 2009, vol 78, S244-S254.
[5] Ardhuin F., B. Chapron and F. Collard, "Observation of swell dissipation across oceans," Geophys. Res. Lett., vol 36, L06607, 2009a.

[6] Ardhuin F., E. Rogers, A. Babanin, J.-F. Filipot, R. Magne, A. Roland, A. V. der Westhuysen, P. Queffeulou, J.-M. Lefevre, L. Aouf, F. Collard, "Semi-empirical dissipation source function for wind-wave models: part 1, definition, calibration and validation at global scales," $J$. of Phy. Oceanogr., vol 40, pp. 1917-1941, 2010.

[7] Lecornu F., Paillet J., Ravenel H., "PREVIMER-Coastal observations and forecast - summary of 2 years demonstration and future perspectives," Proc, Operational Coastal Oceanography conf., Brest, 2008

[8] Hasselmann S., K. Hasselmann, J. Allender ans T. Barnettn "Computation ans parameterizations of the nonlinear energy transfer in a gravity-wave spectrum. part 2: Parameterizations of the nonlinear energy transfer for application in wave model", J. Phys. Oceanogr., vol $15,1378-1391,1985$ 
[9] Tolman, H.L., "Subgrid modeling of moveable-bed bottom friction in wind wave models," Coastal Eng., 26, 57-75, 1995.

[10] Ardhuin, F, W. C. O’Reilly, T. H. C. Herbers, and P. F. Jessen, "Swell transformation across the continental shelf. Part I: Attenuation and directional broadening," J. Phys. Oceanogr., vol. 33, pp. 1921-1939, 2003

[11] Grant, W.D. and Madsen, O.S., "Movable bed roughness in unsteady oscillatory flow," J. Geophys. Res., vol. 87, 0148-0227, 1982.

[12] Madsen, P.A., Y.-K. Poon an d H.C. Graber, "Spectral wave attenuation by bottom friction: Theory," Proc. $21^{\text {th }}$ Int. Conf. Coastal Engineering, ASCE, 492-504, 1988

[13] Wilson,KC, "Friction of wave induced sheet flow," Coastal Eng., 12 371-379, 1989

[14] Ardhuin F., A. Roland, "Coastal reflection, directional spread, and seismoacoustic noises sources," J. Geophys. Res., vol 117(C00J20), 16 pp., 2012.

[15] Loubrieu B., Bourillet J.F., Moussat E., "Bathy-morphologie régional du Golfe de Gascogne et de la Manche, modèle numérique 2008," Ifremer, Brest, Tech. Rep., DCD/GM/CTDI/08-01, 2008.

[16] Saha S. et al, "The NCEP Climate Forecast System Reanalysis," Bulletin of the American Meteorological Society, vol 91, 1015-1057, 2010

[17] Chawla A., A. D. Spindler, H. L. Tolman, "Validation of a thirty yea wave hindcast using the Climate Forecast System Reanalysis winds", Ocean Modell., in press, 2012

[18] Cox A. T., V. J. Cardone, V. R. Swail, "On the use of the Climate Forecast System Reanalysis Wind Forcing in ocean response modeling", in Proceedings: $12^{\text {th }}$ International Workshop on Wave Hindcasting and Forecasting and $3^{\text {rd }}$ Coastal Hazards Symposium, Hawaii, 2011.

[19] Lazure P., Dumas F., "An external-internal mode coupling for a 3D hydrodynamical model for applications at regional scale (MARS)," Advances In Water Resources, 31(2), 233-250, 2008.

[20] Muller H., Pineau-Guillou L., Idier D., "Storm surge modeling strategy along the French (Atlantic and English Channel) coast," Jonsmod 2013 proceedings Ocean Dynamics, Brest, 2012.

[21] Charnock, H., "Wind stress on a water surface," Quart. J. Roy. Meteor. Soc., vol. 81, pp. 639-640, 1955.

[22] Lyard, F., Lefèvre, F., Letellier, T., Francis, O., "Modelling the global ocean tides: modern insights from FES 2004," Ocean Dynamics, 56 (56), 394-415, 2006

[23] Simon, "La marée océanique côtière," Oceanographic Institute Editions, Paris, 433pp, 2007.

[24] Courtier, P., C. Freydier, J.-F.Geleyn, F. Rabier and M. Rochas, "The ARPEGE project at Météo-France," in ECMWF Seminar Proceedings: Numerical methods in atmospheric models, Vol. II, 193-231, 1991

[25] Courtier P, Thepaut J, Hollingsworth A., "A strategy for operational implementation of 4D-VAR, using an incremental approach," $Q J R$ MeteorolSoc, vol. 120, p.1367-1387, 1994.

[26] Seity Y, Brousseau P, Malardel S, Hello G, Bénard P, Bouttier F, Lac C, Masson V (2011) The AROME-France convective scale operational model.Mon Wea Rev 139:976-991.

[27] Queffeulou P. and D. Croizé-Fillon, "Global altimeter SWH data set," Ifremer, Brest, Tech. Rep., 2012. 